\title{
Markets for Pollution Control when Firms Are Noncompliant ${ }^{1}$
}

\author{
Arun S. Malik \\ Bureau of Business and Economic Research, University of Maryland, \\ College Park, Maryland 20742
}

Received April 5, 1988; revised January 23, 1989

\begin{abstract}
The problem of noncompliance and enforcement in transferable discharge permit (TDP) markets has not received much attention. This paper examines the consequences of noncompliance for a TDP market given fairly general assumptions about the characteristics of the enforcement policy in place. The analysis reveals that when firms are noncompliant TDP markets retain their efficiency property only under some fairly stringent conditions. The effect of noncompliance on the equilibrium permit price raises some important questions about the ability of a TDP market to achieve, and remain in, equilibrium when firms are noncompliant. (c) 1990 Academic Press, Inc.
\end{abstract}

\section{INTRODUCTION}

Over the past few years considerable support has developed for establishing transferable discharge permit (TDP) markets for controlling pollution. In addition to criticizing existing standards-based policies on the grounds of allocative inefficiency, many analysts have emphasized the problems of enforcing these policies in the face of widespread noncompliance. ${ }^{2}$ Little attention has been given, however, to the consequences of noncompliance for TDP markets.

The problems encountered in enforcing standards-based policies have been due largely to the technical difficulties in continuously monitoring pollutant emissions and the absence of well-developed mechanisms for assessing penalties for noncompliance. As long as these deficiencies persist, noncompliance and the consequent need for enforcement will be an intrinsic part of any effective pollution control policy.

The first theoretical work on noncompliance and the enforcement of environmental policies is due to Downing and Watson [4]. They present a general model of the effects of alternative implementation and enforcement policies on firm behavior. A more specific model examining the behavior of a risk-neutral, noncompliant firm facing either effluent standards or taxes is presented by Harford [6]. A similar analysis is presented by Storey and McCabe [13] for the case of a risk-averse firm. More recently, Harford [7] and Russell et al. [12] have presented theoretical analyses of several aspects of the enforcement problem.

\footnotetext{
${ }^{1}$ I thank John Boland, Bruce Hamilton, Robert Schwab, and V. Kerry Smith for their helpful comments and suggestions on earlier versions of this paper.

${ }^{2}$ See Downing and Kimball [3], Drayton [5] and Russell et al. [12]. Tietenberg [14] contains a discussion of enforcement issues in the context of TDP markets. There is a large body of literature on environmental policy that is of relevance even though it does not focus on noncompliance and enforcement directly; it includes $[9,11,15]$.
} 
The only formal analysis of noncompliance in a TDP market is by Beavis and Walker [1]. They develop a simple model of a TDP market consisting of risk-neutral firms with stochastic pollutant discharge. The primary aim of their paper is to demonstrate that the frequency of monitoring affects the level of pollutant discharge when discharges are stochastic. ${ }^{3}$

This paper examines the consequences of noncompliance for a TDP market by formally incorporating noncompliant behavior in a standard market model. ${ }^{4}$ It does not attempt to characterize the optimal enforcement policy for such a market. Rather, it examines the effects of noncompliance given fairly general assumptions about the characteristics of the enforcement policy in place.

A simplifying assumption made in the analysis is that the discharges of the firms in the TDP market have identical effects on ambient quality. Achieving a total discharge goal is then equivalent to maintaining a prescribed level of ambient quality, the usual context in which TDP markets are discussed. This assumption merely allows for an economy of notation; relaxing it does not materially alter the results presented.

The paper is organized as follows. The next section presents the model of a noncompliant firm in a TDP market. The firm's optimal pollutant discharges and permit holdings are then characterized in Section 3. The main questions addressed are whether TDP markets retain their efficiency property in the presence of noncompliance, and what the effects of noncompliance are on the equilibrium permit price. The fourth section briefly discusses problems that are likcly to bc encountered in implementing a TDP market when firms are noncompliant. The final section presents the main conclusions of the analysis.

\section{THE MODEL}

The TDP market consists of $n$ firms and a central authority responsible for issuing permits and ensuring that firms do not discharge more than the permitted amount. A total of $s_{T}$ permits is issued by the central authority. These are allocated among the $n$ firms via an auction or some other suitable mechanism. The authority may, for instance, initially distribute permits free and then allow firms to trade them. The firms are assumed to be price takers in the permit market and in their output markets.

The $i$ th firm's profits from engaging in the pollutant generating activity, excluding permit and fine payments, are given by a smooth, strictly concave function $B_{i}\left(w_{i}\right)$ of pollutant discharge. ${ }^{5}$ As is plausible, profits first increase in $w_{i}$, reaching a maximum at $w_{i}^{o}$, and then decline, as it becomes necessary for the firm to devote resources to generating pollution to further raise its discharge level. Clearly, the firm would not operate in the latter region.

\footnotetext{
${ }^{3}$ Bcavis and Walker [1] incorrectly conclude from Harford's [6] effluent tax model that in a TDP market a firm's pollutant discharge is unaffected by changes in the frequency of monitoring when discharge is deterministic (as is assumed here). As established below, pollutant discharge is a function of the frequency of monitoring even when discharge is deterministic.

${ }^{4}$ The type of noncompliance being modeled here is what Drayton [5] refers to as $\mathrm{O} \& \mathrm{M}$ noncompliance: day-to-day discharges in excess of the allowed amount.

${ }^{5}$ Formally, $B_{i}\left(w_{i}\right)=\max _{x}\left[q_{i} x_{i}-c\left(x_{i}, w_{i}\right)\right]$, where $x_{i}$ is the firm's product output and $q_{i}$ is the price it receives for its output. The cost function $c(\cdot)$ is assumed to be strictly convex.
} 
The $n$ firms face a common permit price $r$. Permit holdings are denoted by $s_{i}$, and the number of permits a firm initially receives free, if any, by $s_{i}^{o}$. If a firm is compliant, $w_{i} \leq s_{i}$ and the magnitude of its violation, $v_{i}$, is zero. If a firm is noncompliant, $w_{i}>s_{i}$, and the magnitude of its violation is given by $v_{i}=w_{i}-s_{i}$.

\section{Audit Probability and Penalty for Violations}

The exact amount of pollutant discharged by a firm can be determined by the central authority only by conducting a compliance audit. It is assumed that these audits are unannounced and that firms cannot vary their permit holdings or pollutant discharge levels during an audit.

The central authority's decision on whether or not to audit a firm may depend on a variety of factors. These include the number of permits held by the firm (which is presumably public knowledge) and an estimate of the firm's pollutant discharge. The authority's ability to derive such an estimate, and its accuracy, will depend on the nature of the pollutant, its effects on environmental quality, and the characteristics of the firm's production process.

From the firm's perspective, audits are uncertain. This may be due to intentional randomness in the authority's audit policy or to uncertainty on the firm's part regarding the authority's estimate of pollutant discharges. Thus, a firm's subjective probability of being audited is given, quite generally, by $p_{i}\left(w_{i}, s_{i} ; \theta\right)$, where $\theta$ is a vector of exogenous audit policy parameters set by the central authority. The audit probability functions are allowed to vary across firms.

The presence of $w_{i}$ in the probability function reflects the assumption that the authority's estimate of pollutant discharges is a function of actual discharges. Assuming the estimate is a nondecreasing function of actual discharges, we would expect the audit probability to be nondecreasing in $w_{i}$. The relationship between the level of permit holdings and the audit probability is more difficult to specify. It can be argued that the probability is increasing in $s_{i}$ over some intervals and decreasing over others. I allow for both these possibilities.

It should be noted that the specification of the audit probability function covers the special cases of a constant audit probability, that is, one independent of $w_{i}$ and $s_{i}$, and an audit probability dependent only on the firm's violation size, $v_{i}=w_{i}-s_{i}$. Although the latter specification has considerable intuitive appeal, it can be argued that actual audit probability functions are unlikely to be a function of violation size for at least some range of values of $w$ and $s$ (see [8]).

If audited and found in noncompliance, the firm incurs a certain penalty, the magnitude of which is given by a smoot $\mathrm{L}$, increasing function of the firm's violation size $F_{i}\left(v_{i} ; \delta\right)$, where $\delta$ is a vector of exogenous penalty policy parameters set by the enforcement agency.

\section{Firm's Decision Problem}

Given the audit uncertainty, each firm seeks to maximize its expected utility of profits, $E\left[U_{i}\left(\pi_{i}\right)\right]$,

$$
\max _{w, s}\left[\left(1-p_{i}\right) U_{i}\left(\pi_{i}^{0}\right)+p_{i} U_{i}\left(\pi_{i}^{1}\right)\right],
$$


where

$$
\begin{aligned}
& \pi_{i}^{0}=B_{i}\left(w_{i}\right)-r\left(s_{i}-s_{i}^{o}\right) \\
& \pi_{i}^{1}=\pi_{i}^{0}-F_{i}\left(v_{i} ; \delta\right)
\end{aligned}
$$

and

$$
p_{i}=p_{i}\left(w_{i}, s_{i} ; \theta\right){ }^{6}
$$

\section{OPTIMAL POLLUTANT DISCHARGES AND PERMIT HOLDINGS}

\section{Pollutant Discharge}

Omitting the firm subscript, the first-order conditions for an interior solution to (1) are

$$
\begin{aligned}
(1-p) U^{\prime}\left(\pi^{0}\right) B^{\prime}+p U^{\prime}\left(\pi^{1}\right)\left(B^{\prime}-F^{\prime}\right) & =\frac{\partial p}{\partial w}\left[U\left(\pi^{0}\right)-U\left(\pi^{1}\right)\right] \\
-(1-p) U^{\prime}\left(\pi^{0}\right) r+p U^{\prime}\left(\pi^{1}\right)\left(-r+F^{\prime}\right) & =\frac{\partial p}{\partial s}\left[U\left(\pi^{0}\right)-U\left(\pi^{1}\right)\right] .
\end{aligned}
$$

The complete Kuhn-Tucker conditions for (1) as well as a sufficient condition for a positive violation are presented in the Appendix.

Adding (2) and (3) and rearranging terms yields

$$
B_{i}^{\prime}\left(w_{i}\right)=r+\phi_{i}\left[\frac{U_{i}\left(\pi_{i}^{0}\right)-U_{i}\left(\pi_{i}^{1}\right)}{E\left[U_{i}^{\prime}\left(\pi_{i}\right)\right]}\right]
$$

where $\phi_{i}=\partial p_{i} / \partial w_{i}+\partial p_{i} / \partial s_{i}$. The key expression in this equation is the second term on the RHS. $\phi_{i}$ gives the change in the audit probability from a marginal increase in the discharge level and in permit holdings. The expression in brackets represents the mean monetary value of the difference in utility when not audited and when audited. For a risk-neutral firm, the mean value is simply equal to the fine, $F\left(v_{i} ; \delta\right)$.

Since $\left[U\left(\pi^{0}\right)-U\left(\pi^{1}\right)\right] / E\left[U^{\prime}(\pi)\right]>0$, the sign of the second term depends on that of $\phi_{i}$. As noted earlier, $\partial p_{i} / \partial w_{i}$ is likely to be non-negative, but $\partial p_{i} / \partial s_{i}$ may be positive or negative. Hence, at this level of generality, the sign of $\phi_{i}$ is ambiguous. Note, however, that if

$$
\phi_{i}=\partial p_{i} / \partial w_{i}+\partial p_{i} / \partial s_{i}=0
$$

${ }^{6}$ Setting $s_{i}^{o}=0$, and redefining $r$ to be the effluent tax rate and $s_{i}$ to be reported discharge, (1) becomes a generalized version of the models of an effluent tax evading firm presented by Harford [6] and Storey and McCabe [13]. The key difference between the two models is that the effluent tax rate is presumably exogenous, whereas the equilibrium permit price is endogenous. 
over the relevant range, (4) reduces to

$$
B_{i}^{\prime}\left(w_{i}\right)=r
$$

which is identical to the abatement decision rule employed by a firm that is, by assumption, perfectly compliant. (A compliant firm maximizes $B_{i}\left(w_{i}\right)-r\left(w_{i}-s^{0}\right)$.)

Thus, if $\phi_{i}=0$, the quantity of pollutant discharged by a noncompliant firm for a given permit price is equal to that discharged by an otherwise identical compliant firm, $w_{i}^{*}(r)=\bar{w}_{i}^{*}(r)$, where $\bar{w}_{i}^{*}$ denotes the pollutant discharge of the compliant firm. An obvious corollary to this result is that when $\phi_{i}=0$ the quantity of pollutant discharged by a noncompliant firm does not directly depend on the enforcement policy or on the firm's attitude toward risk. ${ }^{7}$

Although the condition $\phi_{i}=0$ is a fairly stringent one, there are two interesting cases where it does hold. The first is that when over the relevant range the subjective audit probability is a constant, independent of the firm's decisions, then $\partial p_{i} / \partial w_{i}=$ $\partial p_{i} / \partial s_{i}=0$. The second case is that when over the relevant range the audit probability is a function of the firm's violation size, that is, $p_{i}\left(w_{i}, s_{i} ; \theta\right)=g_{i}\left(w_{i}-\right.$ $s ; \theta_{i}$ ), then $\partial p_{i} / \partial w_{i}=g_{i}^{\prime}$ and $\partial p_{i} / \partial s_{i}=-g_{i}^{\prime}$. For these two cases, the abatement decision rule employed by a noncompliant firm is identical to that used by a compliant firm.

In general, however, the presence of the second term on the RHS of (4) drives a wedge between the permit price $(r)$ and marginal profits $\left(B_{i}^{\prime}\right)$. The sign of this term depends on the characteristics of the audit probability function. Its magnitude is determined, in part, by the firm's attitude toward risk. The strict concavity of the profit function implies that if the second term is negative, the quantity of pollutant discharged by a noncompliant firm is larger than that of an otherwise identical compliant firm $\left(w_{i}^{*}>\bar{w}_{i}^{*}\right)$ for a given permit price. Conversely, if the second term is positive, the quantity of pollutant discharged is smaller $\left(w_{i}^{*}<\bar{w}_{i}^{*}\right)$.

\section{Permit Demand and Equilibrium Permit Price}

The above results indicate that, for a given permit price, the quantity of pollutant discharged by noncompliant firms may be equal to or even smaller than the quantity discharged by otherwise identical compliant firms. Yet, by definition, aggregate discharge must be higher in a TDP market in which firms are noncompliant. It is apparent that for these two observations to be reconciled, the equilibrium permit price in a noncompliant TDP market must differ from that in a compliant market.

Examining the first-order condition for $s_{i}$, (3), it is clear that a noncompliant firm's demand for permits, $s_{i}^{*}(r)$, depends on its attitude towards risk and on the

\footnotetext{
${ }^{7}$ When the audit probability is a constant and the firm is risk neutral, the first-order conditions (2)-(3) reduce to $B^{\prime}=p F^{\prime}$ and $r=p F^{\prime}$, i.e., the discharge level is set so that marginal profits equal the marginal expected fine, and permit holdings are chosen so that the marginal expected fine is equal to the permit price. Together, these two conditions imply $B^{\prime}=r$. These results are analogous to those obtained by Harford [6] for the case of a risk-neutral firm facing an effluent tax.
} 
characteristics of the enforcement policy it faces. Hence, the equilibrium permit price will also depend on these factors. ${ }^{8}$

As is true for pollutant discharge, the relationship between a noncompliant firm's permit demand and that of an otherwise identical compliant firm depends on the characteristics of the firm's subjective audit probability function. As established above, if $\phi_{i}$ is non-negative, $w_{i}^{*} \leq \bar{w}_{i}^{*}$. Since $w_{i}^{*}>s_{i}^{*}$ for a noncompliant firm, it follows that $s_{i}^{*}<\bar{w}_{i}^{*}$ when $\phi_{i} \geq 0$; that is, the permit demand of a noncompliant firm is lower than that of an otherwise identical compliant firm. (A compliant firm's permit demand is identical to its pollutant discharge level.) However, if $\phi_{i}$ is negative, $w_{i}^{*}>\bar{w}_{i}^{*}$. Although it is still true that $w_{i}^{*}>s_{i}^{*}$ for a noncompliant firm, this inequality no longer implies an unambiguous relationship between $s_{i}^{*}$ and $\bar{w}_{i}^{*}$. Thus, it is possible when $\phi_{i}<0$ that the number of permits demanded by a noncompliant firm is higher than that demanded by an otherwise identical compliant firm over some range of permit prices (i.e., $w_{i}^{*}>s_{i}^{*}>\bar{w}_{i}^{*}$ ).

The absence of an unambiguous relationship between the permit demands of noncompliant and compliant firms implies that no determinate relationship can be established between the equilibrium permit price in a market with noncompliant firms $\left(r^{*}\right)$ and the equilibrium price in a market with otherwise identical compliant firms $\left(\tilde{r}^{*}\right)$. In particular, one cannot rule out the perverse possibility that the equilibrium permit price in a noncompliant market is higher than that in a compliant market. However, for the special case where $\phi_{i}$ is non-negative for all noncompliant firms in the TDP market, $r^{*}<\bar{r}^{*}$. This is shown below.

The equilibrium permit price in a compliant market is implicitly given by the equation $\sum_{i} \bar{w}_{i}^{*}(r)=s_{\mathrm{T}}$, whereas the equilibrium price in a noncompliant market is given by $\sum_{i} s_{i}^{*}(r)=s_{\mathrm{T}}$. When $\phi_{i}$ is non-negative, $\bar{w}_{i}^{*}>s_{i}^{*}$, hence

$$
\sum_{i} \bar{w}_{i}^{*}\left(r^{*}\right)>\sum_{i} s_{i}^{*}\left(r^{*}\right)=s_{\mathrm{T}}
$$

Since $\bar{w}_{i}^{*}(r)$ is decreasing in $r$ (see (6) and recall $B_{i}^{\prime \prime}<0$ ), it follows that $r^{*}<\bar{r}^{*}$. Thus, when $\phi_{i} \leq 0$ for all noncompliant firms, a condition which is automatically satisfied when audit probabilities are constant or a function of violation size, noncompliance implies a lower equilibrium permit price.

The above analysis indicates that the principal effect of noncompliance in a TDP market is to alter the equilibrium permit price. An important implication of this result is that in TDP markets where the number of firms is small, noncompliance on the part of even one firm in the market may have a significant effect on the pollutant discharge levels of the other firms through its impact on the equilibrium permit price. In such small-numbers cases, one may question the plausibility of the underlying assumption that firms are price takers in the permit market. It could be argued that firms will recognize their influence on permit price and behave accordingly. However, this argument is independent of whether or not firms are noncompliant.

\footnotetext{
${ }^{8}$ Via its effect on the equilibrium permit price, changes in the probability (or frequency) of an audit will clearly influence a firm's discharge level, contrary to what is concluded by Beavis and Walker [1]. Their error stems from overlooking the link between the equilibrium permit price and the enforcement policy.
} 


\section{Efficiency of TPD Markets given Noncompliance}

In principle, when firms are perfectly compliant, TDP markets minimize the cost of achieving a given total discharge level by ensuring that marginal profits with respect to pollutant discharge are equated across firms. However, when firms are noncompliant, marginal profits are equated across firms only if the audit probabilities satisfy (5), with each firm setting its marginal profits equal to the common permit price. This suggests that TDP markets may not be efficient when firms are noncompliant. Before drawing this conclusion we need to establish that equating marginal profits is desirable even when firms are noncompliant.

In a first-best world of perfect compliance, the desirability of equating marginal profits is demonstrated by maximizing a social net benefit function of the form $\left[\sum B_{i}\left(w_{i}\right)-D\left(\sum w_{i}\right)\right]$, where $D(\cdot)$ captures the damages from aggregate pollutant discharges. In such a world, the central authority is assumed to be able to directly control each firm's pollutant discharge. The first-order conditions for this problem require discharge levels to be chosen such that marginal profits are equated across firms and set equal to the marginal damage from pollution.

The relevant benchmark maximization problem in a second-best world where firms are noncompliant is considerably more complicated. It is now inappropriate to assume that the central authority can directly control each firm's pollutant discharge. However, it is reasonable to assume that the authority can indirectly control discharges by issuing non marketable permits to firms, that is, by setting a discharge standard for each firm. Further control over discharges is provided by the authority's choice of enforcement policy. The objective function of the problem changes to the extent that it must also include the costs of enforcement.

Characterizing the solution to the benchmark problem described above requires an analysis of the optimal enforcement policy, which is outside the scope of this paper. The approach adopted here is to examine, instead, a sub-problem of the complete second-best welfare maximization problem: one in which the enforcement policy is taken as given, and only the allocation of nonmarketable permits is variable. The first-order conditions for the solution to this problem are a subset of those for the complete problem.

Since the enforcement policy is taken as given, enforcement costs are a constant and, for our purposes, can be omitted from the objective function. Hence, the objective function is identical in appearance to that for the perfect compliance case,

$$
\max _{s_{i}} \sum_{i=1}^{n} B_{i}\left(\hat{w}_{i}^{*}\right)-D\left(\sum_{i=1}^{n} \hat{w}_{i}^{*}\right)
$$

where $\hat{w}_{i}^{*}=\hat{w}_{i}^{*}\left(s_{i}\right)$ denotes a firm's optimal pollutant discharge level given a fixed number of permits, $s_{i}$. The first-order conditions for an interior solution to this problem are

$$
\left(B_{i}^{\prime}-D^{\prime}\right) \frac{\partial \hat{w}_{i}^{*}}{\partial s_{i}}=0 \quad i=1, \ldots, n .
$$

These differ from the corresponding conditions for the perfect compliance case by the presence of $\partial \hat{w}_{i}^{*} / \partial s_{i}$. They imply, nonetheless, that it is desirable to equate marginal profits even when firms are noncompliant. We can therefore conclude that 
when firms are noncompliant, TDP markets are efficient only when $\phi_{i}=0$ over the relevant range for all firms.

\section{IMPLEMENTING A TDP MARKET WHEN FIRMS ARE NONCOMPLIANT}

As noted earlier, if the number of firms in a TDP market is small, noncompliance on the part of one or more firms in the market may have a significant effect on the discharge levels of other firms in the market through its influence on the equilibrium permit price. As a result, containing the effects of noncompliance may be troublesome in TDP markets with small numbers of participants. Such markets are likely to be the rule rather than the exception.

For example, if a noncompliant firm in such a market revised its subjective audit probability as a result of, say, being caught and fined, its demand for permits will shift, and this shift is likely to alter the equilibrium permit price. For a new equilibrium to be achieved, it may well be necessary for all firms, both noncompliant and compliant, to trade permits and adjust their discharge levels.

Thus, noncompliance may make it even more difficult for a TDP market to achieve an equilibrium or maintain one, and firms may incur significant adjustment costs in modifying their discharge levels in response to changing permit prices. The significance of this problem will depend on the degree to which permit prices are affected by perceived changes in enforcement policy and on the size of permit markets.

Undoubtedly, the stickiness of permit prices will depend on the mechanism adopted for effecting permit trades. It has been implicitly assumed above that the TDP market takes the form of a standard unregulated market where trades occur whenever two or more parties find them advantageous. However, a number of policy analysts have argued that to mitigate problems of market thinness, TDP markets should take the form of periodic auctions conducted by a central authority (e.g., see [2, 10]). A question that arises is how noncompliance would be handled in such a market. Would a special auction be scheduled whenever one or more firms are found in noncompliance to allow them to satisfy their possibly revised permit demands, or would they be required to wait until the next auction? In the first case, the auction-based market would function much like a conventional unregulated one. However, in the second case, firms would effectively face a system of effluent standards between auctions, with each firm's standard given by its existing permit holdings. Hence, any efficiency properties of the TDP market would be undermined between auctions. The significance of this problem clearly will depend on the extent of noncompliance, the frequency with which auctions are held, and the extent to which firms modify their discharge levels in response to perceived changes in the enforcement policy. It is likely that the problem can be mitigated in a carefully designed auction-based market.

\section{CONCLUSIONS}

Starting with a model of a noncompliant firm, I have examined the consequences of noncompliance for a system of transferable discharge permits. The analysis reveals that when firms are noncompliant, TDP markets retain their efficiency 
property only under some fairly stringent conditions. The principal effect of noncompliance on the market itself is to alter the equilibrium permit price. Although it is likely that the equilibrium permit price is lower given noncompliance, it is difficult to rule out the possibility of a higher equilibrium price.

In TDP markets with small numbers of participants, noncompliance on the part of any one firm or group of firms may influence the hehavior of all other firms in the market. This raises some important questions about the ability of a TDP market to achieve and remain in equilibrium when firms are noncompliant. It also implies that careful consideration must be given to noncompliance when designing mechanisms for permit trading.

\section{APPENDIX}

Written out in full, the firm's decision problem is

$$
\begin{aligned}
& \max _{w, s} {\left[(1-p) U\left(\pi^{0}\right)+p U\left(\pi^{1}\right)\right] } \\
& \text { s.t. } w \geq 0, \quad s \geq 0, \quad \text { and } \quad v \geq 0,
\end{aligned}
$$

where $\pi^{0}, \pi^{1}$, and $p$ are as defined in (1). The constraint $v \geq 0$ is included to facilitate deriving a sufficient condition for the firm to choose a positive violation $(v>0)$.

The Kuhn-Tucker conditions for the above maximization problem are

$$
\begin{aligned}
& \frac{\partial L}{\partial w}=(1-p) U^{\prime}\left(\pi^{0}\right) B^{\prime}+p U^{\prime}\left(\pi^{1}\right)\left(B^{\prime}-F^{\prime}\right)-\frac{\partial p}{\partial w}\left[U\left(\pi^{0}\right)-U\left(\pi^{1}\right)\right]+\lambda \leq 0, \\
& \frac{\partial L}{\partial s}=-(1-p) U^{\prime}\left(\pi^{0}\right) r+p U^{\prime}\left(\pi^{1}\right)\left(-r+F^{\prime}\right) \\
&-\frac{\partial p}{\partial s}\left[U\left(\pi^{0}\right)-U\left(\pi^{1}\right)\right]-\lambda \leq 0, \\
&(\partial L / \partial w) w=0, \quad(\partial L / \partial s) s=0, \quad \lambda v=0, \quad \lambda \geq 0, \quad \text { (A-4) }
\end{aligned}
$$

along with the constraints in (A-1). Given $w>0$, which is the only case of interest, a sufficient condition for a positive violation can be derived by substituting $v=0$ in (A-3). This gives

$$
U^{\prime}(\bar{\pi})\left[-r+p F^{\prime}(0)\right]-\lambda=0,
$$

since $\pi^{0}=\pi^{1}=\bar{\pi}$ when $v=0$; (A-3) becomes an equality because $w>0$ and $v=0$ imply $s>0$. Examining (A-5) it is apparent that $v=0$ cannot satisfy the Kuhn-Tucker conditions if $p F^{\prime}(0)<r$ since $\lambda \geq 0$. Hence, a sufficient condition for the firm to choose a positive violation is

$$
p F^{\prime}(0)<r,
$$

that is, the expected marginal fine at a zero violation must be lower than the permit price. 


\section{REFERENCES}

1. B. Beavis and M. Walker, Random wastes, imperfect monitoring, and environmental quality standards, J. Public Econom. 21, 377- 387 (1983).

2. M. David, W. Eheart, E. Joeres, and E. David, Marketable permits for the control of phosphorous pollution into Lake Michigan, Water Resour. Res. 16, 263-270 (1980).

3. P. B. Downing and J. H. Kimball, Enforcing pollution control laws in the U.S., Policy Stud. J. 11, 55-65 (1982).

4. P. B. Downing and W. D. Watson, Jr., The economics of enforcing air pollution controls, J. Environ. Econom. Management 1, 219-236 (1974).

5. W. Drayton, Economic law enforcement, Harvard Environ. Law Rev. 4, 1-40 (1980).

6. J. D. Harford, Firm behavior under imperfectly enforceable pollution standards and taxes, $J$. Environ. Econom. Management 5, 26-43 (1978).

7. J. D. Harford, Self-reporting of pollution and the firm's behavior under imperfectly enforceable regulations, J. Environ. Econom. Management 14, 293-303 (1987).

8. A. Malik, "Noncompliance and the Economic Theory of Pollution Control," unpublished Ph.D. dissertation, Johns Hopkins University, Baltimore, MD (1984).

9. A. McGartland, A comparison of two marketable discharge permits systems, J. Environ. Econom. Management 15, 35-44 (1988).

10. R. G. Noll, Implementing marketable emissions permits, Amer. Econom. Rev., Papers and Proceedings 72, 120-124 (1982).

11. M. J. Roberts and M. Spence, Effluent charges and licenses under uncertainty, J. Public Econom. 5, 193-208 (1976).

12. C. S. Russell, W. Harrington, and W. J. Vaughan, "Enforcing Pollution Control Laws," Resources for the Future, Washington, D.C. (1986).

13. D. J. Storey and P. J. McCabe, The criminal waste discharger, Scot. J. Polit. Economy 27, 30-40 (1980).

14. T. H. Tietenberg, "Emissions Trading," Resources for the Future, Washington, D.C. (1985).

15. G. W. Yohe, Substitution and the control of pollution: A comparison of effluent charges and quantity standards under uncertainty, J. Environ. Econom. Management 3, 312-324 (1976). 